\title{
Using cultural historical activity theory to examine how teachers seek and share knowledge in a peer-to-peer professional development network
}

\author{
Torrey Trust \\ University of Massachusetts, Amherst
}

\begin{abstract}
Many researchers have found that the main reason teachers participate in peer-to-peer professional development networks (PDNs) is to seek and share professional knowledge. Yet, the majority of studies about PDNs focus on how and why teachers participate in these virtual spaces rather than how teachers find and distribute knowledge. Each PDN has its own unique rules, tools, community members, and culture that shape how knowledge is created, organised, curated, and shared. Without understanding the factors that shape how and why knowledge is shared in a PDN, teachers may not be able to access the knowledge they need to grow their practice. This study was designed to examine teachers' knowledge seeking and sharing actions in the Edmodo Math Subject Community, a popular PDN. Cultural historical activity theory was used as a framework for examining the socially constructed actions of seeking and sharing knowledge in a PDN. The findings suggest that seeking and sharing knowledge is a complex, dynamically evolving process that is shaped by the technical (e.g., tools) and social (e.g., community members, rules, roles) aspects of the PDN. Implications and ideas for further research are discussed.
\end{abstract}

\section{Introduction}

Teaching is a complex and challenging job, thus, teachers need ongoing learning opportunities to construct knowledge that will help them stay current with the evolving knowledge domains in their practice (Commission on Teacher Credentialing, 2009). Shulman (1986, 1987) identified six knowledge domains for teachers: content knowledge (e.g., subject matter), pedagogical knowledge (e.g., teaching strategies), pedagogical content knowledge (e.g., combining subject matter knowledge with the understanding of how students learn), curricular knowledge (e.g., understanding the curriculum, including materials and tools), knowledge of learners (e.g., knowing what teaching and learning strategies work for each student), and knowledge of educational contexts (e.g., understanding the sociocultural factors that shape the classroom, school, and local community). Although Shulman's teacher knowledge domains were developed more than three decades ago, they are still relevant today, as the nature of teaching and learning in many school settings has not changed much in 30 years.

Many teachers are participating in peer-to-peer professional development networks in order to expand their professional knowledge and grow their practice (Hew \& Hara, 2007; U.S. Department of Education, Office of Educational Technology, 2011). PDNs are internet-based tools or platforms, such as discussion forums, email list servers, and social media walls (e.g., news feeds), that allow teachers to exchange professional knowledge (Trust, 2015). Teachers typically use PDNs to find and share lesson plans, course materials, digital resources, learning activities, websites, news articles, and other relevant practice-based knowledge (Trust, 2015).

Each PDN consists of a unique composition of sociocultural elements that play an important role in shaping how teachers find and distribute knowledge. Cultural historical activity theorists contend that people's goaloriented actions are mediated by tools and shaped by the sociocultural norms, rules, and divisions of labour within a community (Cole \& Engeström, 1993; Engeström, 1987; Leontiev, 1978; Vygotsky, 1978). As teachers seek to find knowledge in a PDN that will support the growth of their practice, their actions are influenced by their goals, the tools they use, the rules and roles of the community, and the community members' actions. Teachers who understand the various elements that shape how knowledge is found and distributed in a PDN are more likely to acquire knowledge that meets their needs and supports the growth of their practice. Thus, the goal of this study was to examine the sociocultural elements in a PDN that shaped teachers' knowledge seeking and sharing actions in order to provide researchers, administrators, instructional designers, and teachers with insights about how to design and navigate PDNs for professional growth. 


\section{Literature review}

PDNs are web-based tools or platforms that allow teachers to seek and share professional knowledge with peers and experts around the world (Trust, 2015). These tools and platforms allow teachers to break out of their isolated school environments (Carpenter \& Krutka, 2014; Rosenholtz, 1989; Tharp \& Gallimore, 1991) and exchange knowledge with teachers who they might not met otherwise. This process of exploring professional knowledge that is shared by a diverse group of educators allows teachers to gain new insights and resources and stay up-to-date with the latest changes in the field of education (Duncan-Howell, 2010; Forte, Humphreys, \& Park, 2012; Hew \& Hara, 2007; Hur \& Brush, 2009; Visser, Evering, \& Barrett, 2014).

While PDNs are similar to online communities of practice, in that individuals engage in these online spaces to gain professional knowledge and improve their practice, individuals typically engage in one-time, shortlived interactions (e.g., posting a question) in PDNs to find knowledge that meets an immediate interest, need, or goal (Trust, 2015). In contrast, in face-to-face and online communities of practice, members connect, build relationships, mentor one another, engage in sustained conversations, build shared artifacts, and collaboratively work to improve the profession (Johnson, 2001; Riel \& Polin, 2004; Schwier, 2001; Wenger, 1999). Likewise, members in communities of interest (Jones \& Preece, 2006) and affinity spaces (Gee, 2005) engage in long-term, knowledge-building activities around a topic of interest.

Even though PDNs are different from online communities, affinity spaces, and communities of interest, teachers' actions in all of these online spaces are shaped by a variety of factors. Jones and Preece (2006) discovered that membership and participation in online communities were influenced by a variety of social factors, such as etiquette, social presence, empathy, trust, reciprocity, and governance. Carr and Chambers (2006) found that teachers' perceptions of the online community, their ability to use the community platform, and the culture of the community shaped whether teachers participated in the online community. Additionally, Barab, Schatz and Scheckler (2004) found that the social aspects of the community (humanhuman interaction) shaped member participation more significantly than the technical aspects of the community (human-computer interaction). The authors of these studies highlighted the importance of examining the sociocultural contexts in online communities.

Teachers' knowledge seeking and sharing actions always occurs in, and are shaped by, a context (Jonassen \& Rohrer-Murphy, 1999; Vygotsky, 1978; Webster-Wright, 2009). Boud and Walker (1998) consider context to be one of the most influential factors that shapes the learning process. Every PDN has a different context that consists of various interactions among people, tools, and content. It is important to understand how the context of a PDN, and the interactions that occur, shape teachers' abilities to locate and exchange professional knowledge.

Yet, there is a dearth of research in the areas of both teacher learning and PDNs about the contexts that shape how teachers find and share professional knowledge (Webster-Wright, 2009). Many studies about teacher learning focus on the knowledge that teachers need to acquire to become highly effective professionals. These studies often explore the different types of knowledge that teachers need to successfully navigate their profession (Grossman \& Richert, 1988; Kleickman, et al., 2012; Shulman, 1986, 1987) and the ways that teachers gain professional knowledge (e.g., formal and informal learning opportunities) (Cochran-Smith \& Lytle 1999; Kleickmann, et al., 2012; Shulman, 1987; Villegas-Reimers, 2003; Webster-Wright, 2009). Opfer and Pedder (2011) argue that teacher learning needs to be examined using a more complex theoretical framework in order to understand the network of variables that influence the process of acquiring new knowledge. By understanding the complex dynamics of teachers' knowledge seeking and sharing actions within a PDN, researchers and administrators can support teachers in learning how to navigate the complexity of PDNs to find knowledge that will grow their practice.

Divaharan and Lim's (2010) study of the sociocultural contexts influencing teachers' use of information and communication technology (ICT) is an exemplar of how researchers might analyse the process of teacher learning using a more complex framework. Divaharan and Lim used the CHAT framework to examine contradictions, intentionality, and the relationships among the activity system elements in order to demonstrate that teachers' use of ICT is shaped by multiple, overlapping variables within a school system. The findings from their study yielded important insights for the stakeholders (e.g., administrators, school leaders, teachers, students) who were invested in ICT integration within the schools. Thus, in order to 
address the gaps in the literature about PDNs and teacher learning, the researcher selected the CHAT framework for this study to examine the network of sociocultural factors in a PDN that mediate how teachers seek and share knowledge.

\section{Theoretical framework}

Cultural Historical Activity Theory (CHAT) provides a lens for understanding human cognition by examining the dialectical relationships among people, tools, and goals as they influence and are shaped by social structures, culture, and history within the context of a community (Cole \& Engeström, 1993; DeVane \& Squire, 2012; Engeström, 1987). In CHAT, the activity system is the primary unit of analysis (Engeström, 1987). Activity systems are networks of sociocultural elements, with complex mediational structures, that shape the collective actions of individuals who are motivated to achieve a goal (Cole, Engeström, \& Vasquez, 1997; Engeström, 2000; Leontiev, 1978). The common elements within an activity system are: object, outcome, subject, tool, rules, division of labor, and community (see Figure 1) (Cole \& Engeström, 1993; Engeström, 1987). These are explained as follows.

\section{Object and outcome}

CHAT was founded on Vygotsky’s (1978) and Leontiev's (1978) idea of object-oriented action. Leontiev (1978) claimed that human action was structured, motivated, and directed by an external object. The object, or objective, (Nardi, 1996) is the target or product of the activity system. Objects generally surface to meet a human need (Engeström, 2000). The concept of the object provides insight into why people perform different actions (Kaptelinin \& Nardi, 2006). Subjects are motivated to transform objects into outcomes, or desired results (Engeström, 1987).

\section{Subject}

The subject refers to the people engaged in the activity system. The subject can be an individual or a group of individuals (Jonassen \& Rohrer-Murphy, 1999). As subjects pursue the object, their identities and knowledge are shaped and transformed through their interactions with the other elements in the activity system (Davydov, 1999; Roth \& Lee, 2007).

\section{Tools}

Tools mediate every human action and experience (Vygotsky, 1978). Tools can be internal, external, psychological, or material (Kozulin, 1998; Vygotsky, 1978;). Material tools (i.e., new technologies) are the physical items in the external world, while psychological tools (i.e., mental models and symbols) are cognitive strategies used to master higher mental functions (Kozulin, 1998; Vygotsky, 1978). Tools are deeply embedded within the elements of the activity system. When the subject selects a tool to use, the tool defines the way the subject carries out an action (Kaptelinin, Kuuti, \& Bannon, 1995). The subject often shapes and enhances the tool to make it more effective and useful, which then changes the way the subject completes a task (Jonassen \& Rohrer-Murphy, 1999).

\section{Community, division of labour, and rules}

The community refers to the group of individuals with a shared interest or culture that interact within an activity system. The community members negotiate the division of labour and the rules for participation within the community (Jonassen \& Rohrer-Murphy, 1999). Individuals enact different roles within a community since a single individual does not have all of the knowledge and skills necessary to carry out all of the actions within the activity system (Tolman, 1999). Individuals participate in different roles based on their skills, knowledge, and interest (Jonassen \& Rohrer-Murphy, 1999). In addition to the division of labour, each community has a set of collectively negotiated rules, or sociocultural conventions. These conventions are either explicitly stated or implicitly understood guidelines for acting, behaving, and interacting within the community. The rules provide lens for understanding how to become a full participant in a community. 


\section{Contradictions}

Within an activity system, there are internal tensions, or contradictions, that build up over time and lead to the transformation of the system (Engeström \& Miettinen, 1999). According to Roth and Lee (2007), there are four main levels of contradictions that subjects might experience: "internal to one element, between two elements, between two objects, and between two activity systems” (pp. 203-204). When contradictions are brought about consciously, they can lead to a change in one or more of the elements within an activity system, which eventually transforms the whole system (Roth \& Lee, 2007).

Overall, CHAT provides a lens for examining the critical components within an activity system, such as object-orientedness, tool mediation, intentionality, the relational and dualistic nature between the elements, and contradictions (Kaptelinin et al., 1995). By using the CHAT framework as a theoretical lens, researchers can take a more systematic and thorough approach to understanding the factors that shape how teachers seek and share knowledge within a specific context.

\section{Methods}

\section{Research question}

The CHAT framework was used as a guide for exploring the sociocultural factors that influenced how teachers found and shared knowledge in a PDN. The following research question guided the study:

- How is the process of seeking and sharing knowledge shaped by the sociocultural elements within a peer-to-peer professional development network?

\section{Research site}

The Edmodo Math Subject Community (see Figure 2) was selected as the research site because it is a popular PDN. Edmodo is a social networking platform for educators and students. The site has a similar layout to Facebook, including a profile page for all members, but also, it has classroom groups and subject communities. The Math Subject Community (MSC) is one of the 12 subject communities that are available in Edmodo. It provides a space for math educators, and anyone interested in math education, to freely exchange practice-based knowledge. While the MSC is open to individuals around the world, the majority of members tend to be located in the United States. The MSC is catered toward K-12 teachers. The members use the community wall to share information and resources, solicit advice, and post requests for help. The MSC has seen exponential growth. In 2011, it had less than 10,000 members. In early 2014, the number of members exceeded 400,000.

\section{Data collection}

The data collection and analysis strategies were informed by the literature on CHAT. In order to capture the complexity of an activity system, CHAT researchers recommend using a qualitative methodology to collect multiple types of data and ensure that the subject's point of view was included in the study (DeVane \& Squire, 2012; Jonassen \& Rohrer-Murphy, 1999; Nardi, 1996). For this study, the researcher collected three sets of data (online survey responses, interviews, and discussion threads from the MSC) in order to examine the MSC activity system from multiple perspectives. The researcher obtained Institutional Review Board (IRB) approval for the study.

The researcher developed and distributed an online survey in order to gain a broader understanding of the constructs that shaped the members' actions in the MSC. The first page of the survey included a consent form, which provided an overview of the study and asked participants for permission to use the data they provided for the study. All of the participants electronically signed the consent form. The survey included demographic questions (e.g., years of teaching experience, subject, grade level) that provided insight about the subjects and the community factors in the MSC activity system. The survey also featured questions about members' actions in the MSC (e.g., "Why do you visit the MSC?”, "What actions do you perform in the MSC?”, "What types of professional knowledge do you look for when visiting the MSC?”) that provided additional information about the subject, tools, community, and object of the MSC activity system. The 
online survey was posted on the MSC wall over a period of 8 weeks from June to August 2013, during which time 150 individuals completed the survey.

The survey results were used to identify teachers who had experience acquiring knowledge from the MSC and who had visited the MSC more once a month during the previous school year. This "purposive sampling technique” (Lindlof \& Taylor, 2011; p. 109) was used to select participants who had enough familiarity with the MSC and finding and sharing knowledge that they could provide sufficient expertise for the study. A total of 67 participants fit these criteria. These individuals were contacted about participating in a followup interview. A total of 10 respondents agreed to participate in the interview. These respondents participated in 60- to 90-minute interviews. The researcher developed a semi-structured interview guide in order to conduct the interviews in a systematic, yet flexible, way (Patton, 2002). The interview guide included the following four topics with two or more main questions per topic (see Table 1):

1. Information \& Resources

2. Finding Information \& Resources

3. Selecting Information \& Resources

4. Navigating the Online Community

The topics were ordered in a way that would allow participants to walk the researcher step-by-step through the process of locating or sharing knowledge in the MSC. The interview questions were designed to explore the multiple elements within an activity system (see Table 1 ).

Table 1

Interview questions and prompts based on activity system elements

\begin{tabular}{|c|c|}
\hline $\begin{array}{l}\text { Activity } \\
\text { Element }\end{array}$ & Question or Prompt \\
\hline Object & $\begin{array}{l}\text { "When you go to the community, are you looking for anything specific or do } \\
\text { you just browse and see what piques your interest?" }\end{array}$ \\
\hline Tool & $\begin{array}{l}\text { "Please describe how you find information or resources in the Edmodo Math } \\
\text { Subject community." }\end{array}$ \\
\hline Community & "How would you describe the culture of community?” \\
\hline Division of Labour & $\begin{array}{l}\text { "Do people take on different roles?", "Is appropriate to lurk and learn or } \\
\text { should all members give back by sharing knowledge?" }\end{array}$ \\
\hline Rules & $\begin{array}{l}\text { "What are the rules, etiquette, and guidelines that influence how you } \\
\text { participate in the community?" }\end{array}$ \\
\hline
\end{tabular}

The researcher also collected 600 discussion threads from the MSC wall over a period of 9 months. A random selection technique was used in order to draw a representative sample of discussion threads from the MSC and to ensure that the dataset incorporated discussion threads from a variety of individuals. Every week from September 2012 to May 2013, the researcher used a random number generator to determine the day of the week and time of day to collect the 20 latest threads in the MSC. The discussion thread dataset included 600 initial wall posts and 1908 replies to the posts. The discussion thread data was used to triangulate the interview data.

\section{Participants}

\section{Survey participants}

A total of 150 participants filled out the online survey. The majority of the participants were female (88\%) and were located in the United States (89\%). The average age of the participants was 42, with an age range of 23 to 65, and average years of teaching experience of 13 years, with a range of 0 to 38 . All grade levels were represented with $43 \%$ of the participants working in elementary schools (grades K-5), 37\% working in middle schools (grades 6-8) teachers, and 20\% working in high schools (grades 9-12). The grade levels are equivalent to Australian school grades.

\section{Interview participants}

Seven of the participants were middle school teachers (grades 6-8) and the other 3 participants taught at elementary schools (grades K-5) (see Table 2). Eight of the participants were female and 2 were male. The 
number of years spent teaching ranged from 10 to 26, with an average of 16.5 years. The average age of the participants was 43 years old.

Table 2

Demographics of interview participants

\begin{tabular}{|c|c|c|c|c|c|c|}
\hline Pseudonym & Age & $\begin{array}{l}\text { \# Years } \\
\text { Teaching }\end{array}$ & $\begin{array}{l}\text { Grade } \\
\text { Level }\end{array}$ & Subjects Taught & $\begin{array}{l}\text { Year } \\
\text { Joined } \\
\text { Edmodo }\end{array}$ & State \\
\hline Alex & 46 & 21 & 6-8 & $\begin{array}{l}\text { Algebra, Geometry, } \\
\text { Advanced Math }\end{array}$ & 2010 & $\mathrm{IL}$ \\
\hline Andrea & 37 & 13 & 6-7 & Math, Language Arts & 2012 & MI \\
\hline Cecilia & 46 & 12 & 7 & Math Common Core & 2012 & CA \\
\hline Christine & 35 & 10 & 8 & $\begin{array}{l}\text { Algebra, Social Studies, } \\
\text { Avid }\end{array}$ & 2011 & GA \\
\hline Grace & 46 & 11 & $5-6$ & $\begin{array}{l}\text { Math, Reading, Language } \\
\text { Arts }\end{array}$ & 2013 & IA \\
\hline James & 42 & 18 & 4 & Math, Science & 2010 & TX \\
\hline Megan & 46 & 26 & 8 & Algebra & 2011 & $\mathrm{TN}$ \\
\hline Mia & 43 & 13 & 8 & 8th Grade Math & 2012 & GA \\
\hline Rachel & 49 & 17 & 7 & 7th Grade Math & 2012 & TX \\
\hline Sarah & 46 & 24 & $3-5$ & $\begin{array}{l}\text { Advanced Topics } \\
\text { Elementary }\end{array}$ & 2012 & $\mathrm{AL}$ \\
\hline
\end{tabular}

While the interview participants shared many of the same characteristics of the survey population, such as number of years taught, grade level, average age, and gender, they reported visiting the MSC more frequently during the previous school year and making use of the knowledge from the MSC more often.

\section{Data analysis}

The researcher conducted a theoretical thematic analysis (Braun \& Clarke, 2006) of the survey data in order to identify the sociocultural contexts that influenced how teachers found and shared knowledge in the MSC. The researcher imported the survey data into an Excel spreadsheet. After reading through the data, the researcher used the CHAT framework to generate initial codes (e.g., subject, tools, object, community). The researcher then examined the dialectical relationships among the codes in order to gain a broader understanding of the complexity of the MSC activity system. This was done by creating relationship codes for each element (e.g., subject-tool, subject-object, subject-rules) and then identifying and examining the data that fit within these codes. The researcher conducted member checking of the interviews in order to examine the interpretive validity of the findings. The researcher used the results from the data analysis to answer the research question.

\section{Results}

Overall, the object-oriented action of finding new knowledge was influenced by a network of elements in the MSC activity system that interacted with and mutually constituted one another. Figure 1 presents the emergent themes. The following sections will detail each of the elements in the MSC activity system and how they shaped teachers' knowledge seeking and sharing actions. 


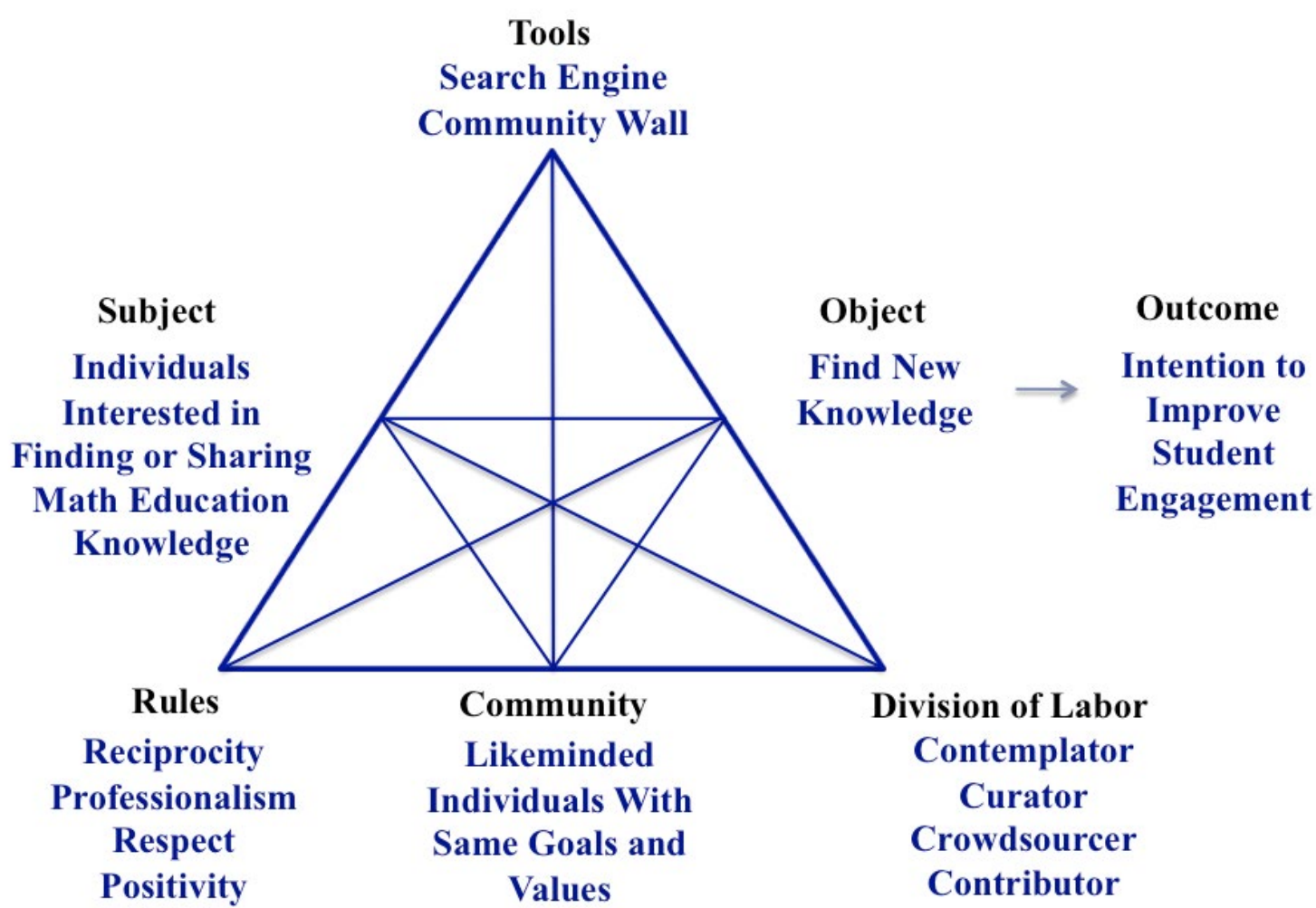

Figure 1. The Edmodo Math Subject Community activity system elements

\section{Object}

Teachers' actions within the MSC were shaped by the object of finding new knowledge, with the intended outcome of improving student engagement in learning math. The survey participants were asked to share what motivated them to visit the MSC. The majority of survey participants (87\%) reported that they visited the MSC to "find new ideas and resources." All 10 interview participants shared the same goal of finding new knowledge to implement in their classrooms. The majority of interview participants felt that math was boring or too abstract for their students to learn, and therefore, they needed to find new resources and learning activities that would improve student engagement. The object of finding new knowledge was also evident throughout the 600 discussion threads. Fifty-four percent of the discussion threads included a request for knowledge (e.g., "Hey, I'm looking for a creative way to teach my students how to find missing dimensions on a right triangle. Any ideas?”), while the remainder of the threads consisted of members sharing knowledge (e.g., "Here are 2 days of Thanksgiving warm-ups if anyone is interested for Monday and Tuesday.”).

\section{Subject}

The subjects were teachers, higher education faculty, teacher educators, and anyone interested in exchanging professional knowledge related to math education. The subjects engaged in actions that allowed them to mutually evolve with the MSC activity system. Each subject brought a different background, experience, and expertise into the MSC. As the subject browsed the community wall and learned from other members, the subject's knowledge may change, and thus, the subject has changed. This meant that every visit to the MSC might change the subject. For example, Rachel, a seventh grade math teacher commented, "Every night, I find a couple things [on Edmodo], and that's more than I had before. So, I'm constantly adding to my knowledge base and resources." Rachel was constantly learning and growing with the MSC. She shared, "the Edmodo math subject community has helped me be a better, more innovative, teacher." However, the process of acquiring knowledge was not a one-way transaction. Rachel noted, "I teach gifted children, so I know how hard it is to meet their needs in the regular classroom, so whenever teachers are looking for what to do to extend learning, I end up sharing a lot of that stuff." Rachel had unique knowledge (e.g., teaching gifted children) that she shared with the MSC and this shaped the stream of knowledge in the MSC. Thus, Rachel and the MSC mutually shaped one another. 


\section{Tools}

The MSC provided two tools to help teachers find and share knowledge: a search engine and the community wall (see Figure 2).

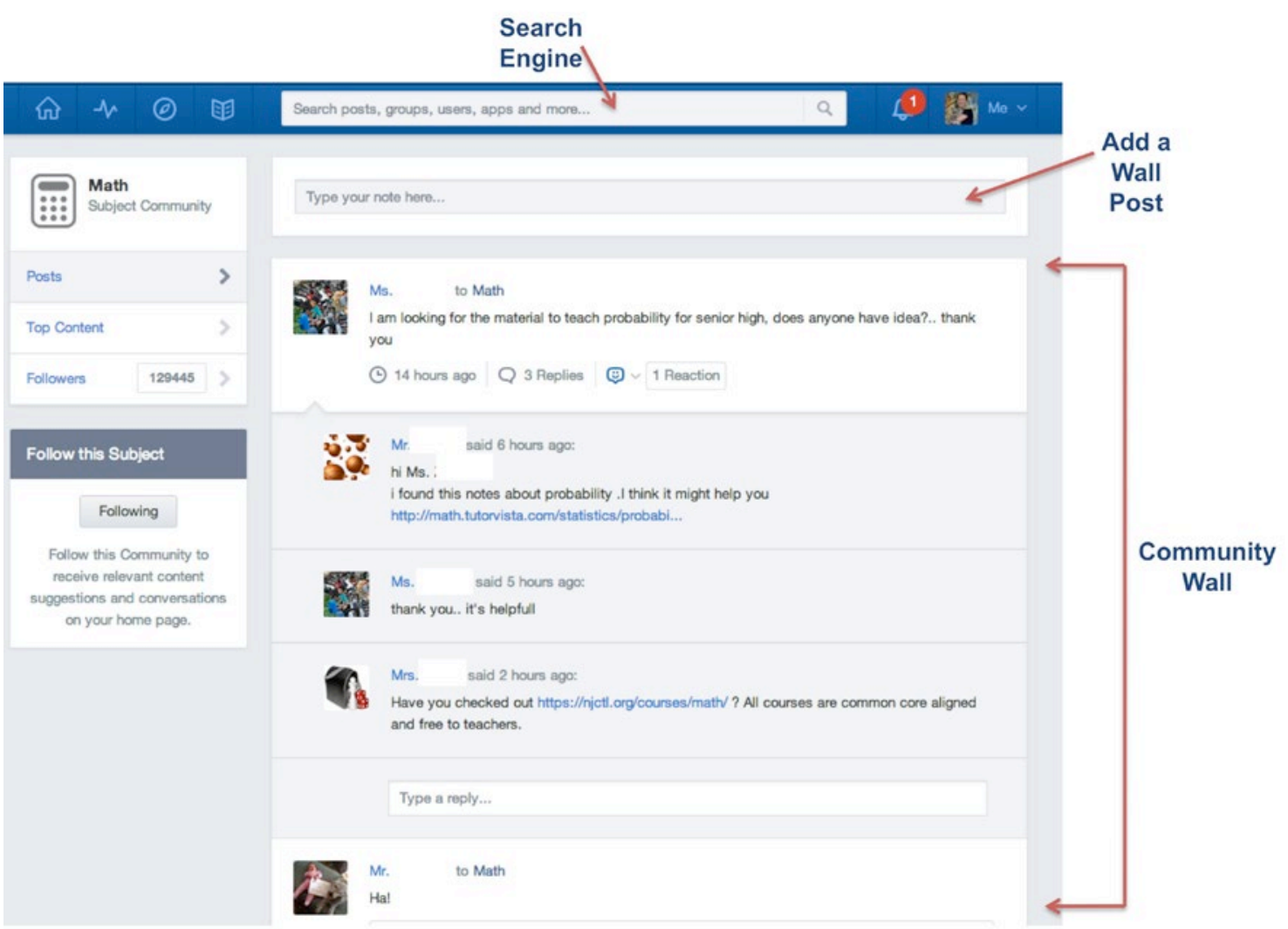

Figure 2. Edmodo Math Subject Community screenshot

\section{Search engine}

The search engine allowed members to search the entire Edmodo site, including all 12 subject communities. Members could use the search engine to quickly find specific knowledge instead of having to browse through the disorganised posts on the MSC wall. However, the search engine did not seem to be a popular tool for acquiring knowledge in the MSC. Only 20\% of the interview participants and 35\% of the survey respondents reported using the Edmodo search engine to find specific posts. Sixty percent of the interview participants stated that they were not aware of the search engine.

\section{Community wall}

The community wall was a virtual space for members to post questions and share resources. The community wall was frequently populated with new discussion threads. Members shared knowledge by posting on the community wall or replying to a post. Posting was the action of writing text and sharing it with the community. Anything that was posted on the community wall was visible to all community members. Members could embed uploaded documents, hyperlinks to external websites, and share resources from their Edmodo library in a wall post.

An overwhelming majority of the survey participants (92\%) and all ten interview participants reported that they found new knowledge by reading the community wall discussion threads. The interview participants reported that the constant change and timeliness of the community wall was a motivating factor for visiting the MSC. The participants liked the community wall's changing stream of knowledge because every time they visited, they found something "fresh," "new," and "different." Some of the interview participants visited the MSC on different days and different times of the day in order to access a wider range of shared 
knowledge. Alex, a middle school math teacher, shared that he visited the MSC multiple times every week in order to acquire more knowledge: "If you go in [to the MSC] on Sunday and you don't find anything, you might find more on Tuesday." Alex felt that frequent visits to the MSC, at varying times, allowed him to gain knowledge from a broader audience.

\section{Community}

The MSC community consisted of a large, diverse group of individuals who had a shared vision or purpose. Cecilia, a middle school math teacher, shared that members were "all there for the same purpose," and that they "all ultimately have the same goal and want the same things." Sarah, an elementary advanced topics teacher, described the members in the community as "people who are just like me." According to the interview participants, the community was made up of a group of individuals who shared the same values, goals, and experiences.

\section{Division of labour}

According to the survey demographic data, the participants brought a wide range of knowledge and experiences to the MSC. The participants' knowledge and experiences varied depending on their profession, years of teaching experience, and subjects and grade levels taught. Since the MSC consisted of members with varying degrees of expertise and experiences, members were able to find more diverse types of knowledge.

Additionally, the MSC members performed different roles within the MSC. Examination of the discussion threads revealed that there was a small group of members who actively asked for and shared knowledge on the MSC wall and there was a large group of members who viewed the shared knowledge but did not contribute to the wall. The community wall only had 5 to 10 new posts every day and the average number of replies per post was 4.9. However, MSC had hundreds of thousands of members. The posts with resources, such as links to external websites or uploaded documents, often had view counts in the thousands. In order to learn more about these two groups of members, the survey and interview participants were asked to describe their knowledge seeking and sharing actions within the MSC. The survey and interview participants described four different roles that they performed in the MSC. A new taxonomy was developed to describe these roles (see Table 3). The Four C's of Participation Taxonomy features the participant roles: contemplator, curator, crowdsourcer, and contributor.

Table 3

The Four C's of Participation

\begin{tabular}{ll}
\hline Role & Description \\
\hline Contemplator & An individual who reads and assesses the shared knowledge in the community. \\
Curator & An individual who collects and organises shared knowledge from the community. \\
Crowdsourcer & $\begin{array}{l}\text { An individual who posts a request for action and pools the wisdom of the crowd to } \\
\text { find a solution, resource, or idea. }\end{array}$ \\
& $\begin{array}{l}\text { An individual who replies to requests for action or shares best practices, links, } \\
\text { resources, and other relevant knowledge with the community. }\end{array}$ \\
\hline
\end{tabular}

Contemplators were members who perused the discussion threads in the MSC. These individuals are often referred to in the literature as lurkers (Lucier, 2012). The interview participants described these individuals as voyeurs, stalkers, and observers. Megan shared how her actions fit within the contemplator role: "I guess I'm probably act more as a voyeur. For the most part, I'm just on the outside looking in, trolling to see what other people have posted." Contemplators actively browsed through the shared knowledge on the community wall or used the search engine to explore various topics. They analysed the shared knowledge and contemplated how they could use the knowledge in their classrooms. They were not simply passive observers. 
Curators were similar to contemplators; however, they actively assessed, collected, and organised the shared knowledge in the MSC. Curators used external tools, such as LiveBinders, Symbaloo, email, or the Edmodo Library, to save, categorise, and organise shared knowledge. Eight of the 10 interview participants described how they curated the shared knowledge from the MSC. The following quotes highlight the different tools that the interview participants used to curate shared knowledge:

I put new ideas and resources in a bit.ly list. I have some sites that I put in Livebinder also. I'm basically just curating information. (Sarah)

I've got one Symbaloo setup for each math standard which has all the games, activities, lessons, quizzes, and everything that you would need to do to introduce, cover, flesh out, RTI, differentiate that standard. (Grace)

I probably have 400 math games bookmarked on my school website and I have teachers across the district tell their kids, 'Go to Ms. T's website' because they know that I've found games and resources for all of the math topics they cover. (Rachel)

Curators used external tools to collect and organise the shared knowledge in the MSC in order to access the knowledge at a later point or to share the knowledge with students, colleagues, or other networks.

Crowdsourcers were individuals who solicited advice, feedback, ideas, or resources by posting a request for help or action (e.g., "I need a resource for multiplication”) on the community wall. A little more than half of the MSC wall posts that were examined were requests for action $(n=321)$, which demonstrated that many members were actively seeking knowledge by posting on the community wall. Grace shared how posting a request for action in the MSC was her main way of finding knowledge: "I usually just put a question there [on the MSC community wall] because you just get immediate responses." Grace felt that posting a request for action and pooling the wisdom of the crowd allowed her to receive quick responses that were geared towards her specific needs.

Contributors were individuals who shared knowledge by posting in the MSC or responded to members' requests for action. Contributors believed that it was important to give back to the MSC. Sarah shared how she was willing to respond to other member's posts if she felt that she could help them. Rachel and Christine shared how they frequently posted on the community wall and participated in discussion threads. Many Contributors also bridged multiple communities and networks. James, Alex, and Grace reported that they frequently found new ideas and resources from their online and face-to-face communities and shared this knowledge with the MSC. Forte, Humphreys, and Park (2012) described these types of teachers as "conduits" (p.7) who moved information, resources, and best practices back and forth between online communities of practice and their school communities.

The roles that members performed in the MSC varied. As members become more comfortable and familiar with using the tools in the MSC, they were more likely to advance through the four C's of participationmoving from contemplator to contributor. However, these roles were flexible. Members could be a curator during one visit to the MSC and then a contributor during the next. The interview participants often performed different roles depending on their goals, amount of free time, and comfort with using the various tools in the MSC.

The participants' roles shaped the way they used the MSC tools to acquire knowledge. The participants who described themselves as contemplators and curators were typically only willing to browse the community wall to find knowledge. The participants who described themselves as crowdsourcers posted requests for action on the community wall. Contributors actively exchanged knowledge and engaged in conversations in the MSC.

Each of these four roles also played a part in shaping the MSC activity system. Contributors shared knowledge, which kept the MSC wall new and fresh and motivated members to return to the MSC. Crowdsourcers encouraged members to share their knowledge by posting requests for action. Curators and Contemplators increased the social presence in the community by actively clicking on the wall posts, which in turn, increased the contributors’ willingness to share more knowledge. 
Overall, the MSC consisted of a large, diverse community of members with different professions, knowledge, skills, and years of teaching experience. These members took on different roles depending on the object they were pursuing and these roles shaped the process of acquiring knowledge.

\section{Rules}

When asked about the rules for participating in the community, the interview participants were not aware of any explicit rules. The Edmodo website has a User Trust \& Safety FAQ (https://support.edmodo.com/home\#forums/20929590-user-trust--safety-faq), which describes the privacy and safety rules and how members can report inappropriate content, language, or members, and cyberbullying. None of the participants were aware of this resource. However, the interview participants described two main implicit rules that shaped members' actions within the MSC: professionalism and reciprocity.

\section{Professionalism}

All of the interview participants described the MSC as a professional community. The interview participants used the term professional to describe a practice-based community with members who were positive, respectful, and helpful. The following two quotes provide examples of the implicitly enacted rule of professionalism that shaped the members' actions:

I had noticed that people tend to be very positive. You don't get the negativity that sometimes comes with social media, like Facebook. You know people are professional and helpful. I don't really notice a lot of spam or things of that nature. (Andrea)

I believe the culture of the community is generally helpful and supportive. The comments are positive, professional, and respectful. I have never seen any spam, or anyone pushing an inappropriate agenda. I haven't witnessed any negative language. (Grace)

Grace and Andrea felt encouraged and empowered to participate in the MSC because all of the members in the MSC shared an implicit understanding that posts and replies should be positive, professional, and helpful.

\section{Reciprocity}

The interview participants also shared that there was an implicitly understood rule that members should give back to the MSC. The participants felt that members should not only be willing to help other members in the MSC, but also that they should share high-quality resources and ideas. Alex described how he would pilot test a resource with one of his other online communities and if other teachers liked it, he would share the resource in the MSC. Alex made sure that the resources he shared were well received by his other networks before sharing them with the MSC. He explained how individuals who posted self-promoting material or poor quality resources had a bad reputation in the MSC. Additionally, 7 of the interview participants explained how there was a general understanding that if someone needed help, members should be willing to respond and provide assistance. This notion of reciprocity was essential to maintaining an active knowledge sharing community.

Overall, the interview participants depicted the MSC as a safe, professional community where they could share knowledge and connect with members without worrying about negativity. There seemed to be an implicit understanding in the MSC that members should be collegial and posts and comments should not be negative. The participants felt that since everyone in the MSC shared the same vision and purpose, the sociocultural norms for participating were relatively straightforward: stay positive, respond and help other members, and do not post spam. These implicit community rules motivated members to give back, share high quality resources, and act professionally and respectfully.

\section{Contradictions}

The participants identified multiple contradictions among the elements in the MSC activity system. The most prominent contradiction occurred within the subject-tool-object relationship. The main tool that members used to look for and share knowledge in the MSC was the community wall. However, the community wall was an unorganised stream of knowledge that featured only 20 to 30 of the latest discussion 
threads. This meant that members only saw the most recent threads relative to when they logged in to visit the MSC. If a member had a specific objective (e.g., find a fractions video for fourth grade students), the chances in which that information would be posted on the community wall at the exact time the member needed it were slim. Alex noted that this was a frustrating aspect of the MSC:

I'm more interested in where can I find the site to get the specifics tailored to me. Because when I turn on Edmodo and you've got how to solve an equation with variables on both sides, what are the odds that that's what I'm looking for now? One in 365 days.

Meanwhile, the search engine could be used as a tool to explore all of the posts in the MSC. Yet, the majority of participants did not use this tool, either due to lack of awareness or lack of knowledge about how to use it. Thus, the tool that the subject selected significantly shaped, and often limited, the subject's ability to pursue the object. As a result, participants had to devise solutions, such as visiting the MSC on different days and times to connect with a wider network, posting a request for action to obtain specific knowledge, and using third-party curation tools, such as Symbaloo, to collect and organise the resources, ideas, and information shared in the MSC. This resulted in a change in the MSC activity system with the introduction of new roles: the crowdsourcer and the curator.

\section{Discussion}

Previous studies about PDNs, online communities, and teacher learning have generally focused on discrete variables and cause-and-effect relationships. Yet, these studies do not do justice to the complexity of the teaching profession. One of the benefits of using the CHAT framework as a theoretical lens was being able to look at a PDN as a complex and evolving activity system. The findings from this study demonstrated that the subjects engaged in actions that allowed them to mutually evolve with the MSC activity system. As the subjects acquired new knowledge from the MSC, their expertise changed, which in turn, changed the way they interacted with the other elements in the PDN activity system. Additionally, when the subjects faced contradictions, they found ways to overcome these tensions (e.g., enacting new roles), which resulted in changes to the MSC.

Another strength of using the CHAT framework was being able to examine teachers' actions within a complex system of elements. The findings from this study demonstrate that teachers' knowledge seeking and sharing actions within the MSC were mediated by multiple sociocultural elements. The tools shaped how teachers found knowledge. The community members' actions and expertise influenced what types of knowledge participants were able to find. The community rules created a positive, professional culture, which shaped members' knowledge sharing actions. Meanwhile, members enacted four roles that influenced how knowledge was organised, shared, and found. These findings support previous studies by Barab, Schatz, and Scheckler (2004), Carr and Chambers (2006), and Jones and Preece (2006), who found that the social (e.g., community) and technical (e.g., tools) aspects of a community influence teachers' actions in online communities.

It is critical that teachers learn to examine the elements that shape how knowledge is accessed and shared in a PDN. Teachers who do not understand the social, cultural, and technical aspects of a PDN risk not being able to find knowledge to achieve their professional goals. For example, teachers who do not adhere to the community rules might be banned, ignored, or seen as less credible, which significantly limits their ability to seek out knowledge. Teachers who do not understand how and why knowledge is organised, curated, and shared might be more likely to come across inaccurate, misleading, or biased knowledge that might negatively impact their practice. Additionally, teachers who do not know how to use the different tools in the community to find and share knowledge will be restricted in achieving their goals. In this study, teachers who just browsed the community wall were limited to finding knowledge that had been shared recently by other members.

As more and more K-12 teachers turn to PDNs to acquire knowledge that they cannot find elsewhere, it is important that these teachers learn to unpack the complexity of a PDN and understand how the various sociocultural elements within these spaces shape their ability to achieve their knowledge seeking and sharing goals. This can be done by asking questions about, observing, and critically examining the different elements within the PDN activity system. The CHAT framework can be used as a guide for educators to analyse the contexts and influential elements within various virtual spaces. For example, teachers can 
examine the tools (e.g., "How do members use the tools to find, organise, curate, and distribute information?"), rules (e.g., "What are the rules, etiquette, and guidelines that influence how members participate in the community?"), and division of labor (e.g., "How do the community members enact different roles?") to better understand how knowledge is shared and found in a PDN. Teacher education programs might consider incorporating action research about PDNs, using CHAT as an analytical guide, to help teachers acquire this knowledge. Additionally, teacher educators should find ways to provide ongoing support to K-12 teachers as they use these spaces for professional growth. This could be done by organising a professional learning community for K-12 teachers to meet face-to-face on a weekly or monthly basis to collaboratively analyse PDNs for educators.

However, PDNs are not limited to K-12 teachers. Many higher education faculty use PDNs as a tool for exchanging professional knowledge (e.g., faculty learning communities) or setup PDNs for students in their courses. There are also student-driven PDNs, which allow students to exchange academic knowledge related to a course. When setting up a PDN, it is helpful to understand the various elements at play that can shape participation and the exchange of knowledge. For example, simply setting up a discussion forum or list serve for a course without establishing community rules or roles, providing support for using the tools, or identifying the object of the PDN could result in low participation or off-task behavior. Additionally, changing one element (e.g., new community members, new tools, new rules) can change the other elements as well as the entire activity system and contradictions between elements can lead to the evolution of the activity system. Therefore, faculty, instructional designers, researchers, and students who create PDNs could use the CHAT framework to critically examine how these elements might shape the acquisition and exchange of knowledge and develop ways to support and encourage members.

While this study provides important insights about the complexity of teachers' knowledge seeking and sharing actions in a PDN, there were multiple limitations that influenced the findings. This study was limited by a non-random sample of survey and interview participants, a small sample size, and a focus on participants in the math subject community. The non-random sampling technique was used in order to ensure participants had sufficient knowledge and expertise related to the study. The small sample size was due in part to collecting data via an optional online survey and having a limited number of respondents who fit the purposive sampling criteria and were willing to participate in the follow-up interview. Three sets of data (survey, interview, MSC discussion threads) were collected in order to overcome the limitations of a small sample size and obtain a more holistic view of the MSC. Additional research is needed with a larger random sample in order to generalise the findings to a broader population. Also, the study focused on participants in the Math Subject Community. Edmodo has 12 subject communities and there are countless other PDNs that can be examined. Future studies are needed to examine whether the findings from this study are consistent with the knowledge seeking and sharing actions of members in other PDNs.

\section{Conclusion}

With the increasing number of social networking sites and web 2.0 tools, higher education faculty, students, and K-12 teachers have access to a variety of PDNs. Research has shown that PDNs are useful tools for finding and sharing knowledge. However, each PDN has its own culture, rules, community, and set of tools that shape members' knowledge seeking and sharing actions. By taking the time to understand the network of elements within a PDN, teachers can access the knowledge they need to grow their practice more easily and researchers and instructional designers can develop more effective PDNs to support teacher and student learning.

\section{References}

Barab, S., Schatz, S., \& Scheckler, R. (2004). Using activity theory to conceptualize online community and using online community to conceptualize activity theory. Mind, Culture, and Activity, 11(1), 2547. http://dx.doi.org/10.1207/s15327884mca1101_3

Boud, D., \& Walker, D. (1998). Promoting reflection in professional courses: The challenge of context. Studies in Higher Education, 23(2), 191-206. http://dx.doi.org/10.1080/03075079812331380384

Braun, V., \& Clarke, V. (2006). Using thematic analysis in psychology. Qualitative Research in Psychology, 3(2), 77-101. http://dx.doi.org/10.1191/1478088706qp063oa 
Carpenter, J. P., \& Krutka, D. G. (2014). How and why educators use Twitter: A survey of the field. Journal of Research on Technology in Education, 46(4), 414-434. http://dx.doi.org/10.1080/15391523.2014.925701

Carr, N., \& Chambers, D. P. (2006). Teacher professional learning in an online community: The experiences of the national quality schooling framework pilot project. Technology, Pedagogy and Education, 15(2), 143-157. http://dx.doi.org/10.1080/14759390600769094

Cochran-Smith, M., \& Lytle, S. L. (1999). Relationships of knowledge and practice: Teacher learning in communities. Review of Research in Education, 24, 249-305. http://dx.doi.org/10.2307/1167272

Cole, M., \& Engeström, Y. (1993). A cultural-historical approach to distributed cognition. In G. Salomon (Ed.), Distributed cognitions: Psychological and educational considerations (pp. 1-46). Cambridge, United Kingdom: Cambridge University Press.

Cole, M., Engestrom, Y., \& Vasquez, O. (Eds.). (1997). Mind, culture, and activity: Seminal papers from the Laboratory of Comparative Human Cognition. Cambridge, MA: University Press.

Commission on Teacher Credentialing. (2009). California standards for the teaching profession. Retrieved from http://www.scusd.edu/sites/main/files/file-attachments/cstpreport.pdf.

Davydov, V. V. (1999). The content and unsolved problems of activity theory. In Y. Engeström, R. Miettinen, \& R. Punamäki (Eds.), Perspectives on activity theory (pp. 39-52). New York, NY: Cambridge University Press.

DeVane, B., \& Squire, K. (2012). Activity theory in the learning technologies. In D. Jonassen, \& S. Land (Eds.), Theoretical foundations of learning environments (pp. 242-268). New York, NY: Routledge.

Divaharan, S., \& Lim, C. P. (2010). Secondary school socio-cultural context influencing ICT integration: A case study approach. Australasian Journal of Educational Technology, 26(6), 741-763. http://dx.doi.org/10.14742/ajet.1040

Duncan-Howell, J. (2010). Teachers making connections: Online communities as a source of professional learning. British Journal of Educational Technology, 41(2), 324-340. http://dx.doi.org/10.1111/j.1467-8535.2009.00953.x

Engeström, Y. (1987). Learning by expanding. An activity-theoretical approach to developmental research. Helsinki, Finland: Orienta-Konsultit Oy.

Engeström, Y. (2000). Activity theory as a framework for analyzing and redesigning work. Ergonomics, 43(7), 960-974. http://dx.doi.org/10.1080/001401300409143

Engeström, Y., \& Miettinen, R. (1999). Introduction. In Y. Engeström, R. Miettinen, \& R. Punamäki (Eds.), Perspectives on activity theory (pp. 1-19). New York, NY: Cambridge University Press. http://dx.doi.org/10.1017/cbo9780511812774.002

Forte, A., Humphreys, M., \& Park, T. (2012, May). Grassroots professional development: How teachers use Twitter. Paper presented at the Sixth International AAAI Conference on Weblogs and Social Media, Dublin, Ireland.

Gee, J. P. (2005). Semiotic social spaces and affinity spaces. In D. Barton, \& K. Tusting (Eds.) Beyond communities of practice language power and social context (pp. 214-232). New York, NY: Cambridge University Press. http://dx.doi.org/10.1017/CBO9780511610554.012

Grossman, P. L., \& Richert, A. E. (1988). Unacknowledged knowledge growth: A re-examination of the effects of teacher education. Teaching and Teacher Education, 4(1), 53-62. http://dx.doi.org/10.1016/0742-051X(88)90024-8

Hew, K., \& Hara, N. (2007). Empirical study of motivators and barriers of teacher online knowledge sharing. Educational Technology Research \& Development, 55(6), 573-595. http://dx.doi.org/10.1007/s11423-007-9049-2

Hur, J. W., \& Brush, T. A. (2009). Teacher participation in online communities: Why do teachers want to participate in self-generated online communities of K-12 teachers? Journal of Research on Technology in Education, 41(3), 279-303. http://dx.doi.org/10.1080/15391523.2009.10782532

Jonassen, D. H., \& Rohrer-Murphy, L. (1999). Activity theory as a framework for designing constructivist learning environments. Educational Technology Research and Development, 47(1), 6179. http://dx.doi.org/10.1007/BF02299477

Jones, A., \& Preece, J. (2006). Online communities for teachers and lifelong learners: A framework for comparing similarities and identifying differences in communities of practice and communities of interest. International Journal of Learning Technology, 2(2), 112-137. http://dx.doi.org/10.1504/IJLT.2006.010615

Johnson, C. M. (2001). A survey of current research on online communities of practice. Internet and Higher Education, 4, 45-60. http://dx.doi.org/10.1016/S1096-7516(01)00047-1 
Kaptelinin, V., Kuutti, K., \& Bannon, L. (1995). Activity theory: Basic concepts and applications. Human-Computer Interaction, 1015, 189-201. http://dx.org/10.1007/3-540-60614-9 14

Kaptelinin, V., \& Nardi, B. A. (2006). Acting with technology. Cambridge, MA: MIT Press.

Kleickmann, T., Richter, D., Kunter, M., Elsner, J., Besser, M., Krauss, S., \& Baumert, J. (2012). Teachers' content knowledge and pedagogical content knowledge: The role of structural differences in teacher education. Journal of Teacher Education, 64(1), 90-106. http://dx.doi.org/10.1177/0022487112460398

Kozulin, A. (1998). Psychological tools: A sociocultural approach to education. Cambridge, MA: Harvard University Press.

Leontiev, A. (1978). Activity, consciousness, and personality (M. Hall, Trans), Englewood Cliffs, NJ: Prentice-Hall.

Lindlof, T. R., \& Taylor, B. C. (2011). Qualitative communication research methods. Thousand Oaks, CA: Sage Publications.

Lucier, R. (2012, June 5). Seven degrees of connectedness. [Blog Post]. Retrieved from http://thecleversheep.blogspot.com/2012/06/seven-degrees-of-connectedness.html.

Nardi, B. A. (1996). Activity theory and human-computer interaction. In B. Nardi (Ed.) Context and consciousness: Activity theory and human-computer interaction (pp. 7-16). Cambridge, MA: MIT Press.

Opfer, V. D., \& Pedder, D. (2011). Conceptualizing teacher professional learning. Review of Educational Research, 81(3), 376-407. http://dx.doi.org/10.3102/0034654311413609

Patton, M. Q. (2002). Qualitative research and evaluation methods. Thousand Oaks, CA: Sage Publications.

Riel, M., \& Polin, L (2004). Online learning communities: Common ground and critical differences in designing technical environments. In S. Barab, R. Kling, \& J. Gray (Eds.). Designing for virtual communities in the service of learning (pp. 16-52). Cambridge, MA: Cambridge University Press.

Rosenholtz, S. (1989) Teachers' workplace: The social organization of schools. New York, NY: Teachers College Record.

Roth, W. M., \& Lee, Y. J. (2007). "Vygotsky’s neglected legacy”: Cultural-historical activity theory. Review of Educational Research, 77(2), 186-232. http://dx.doi.org/10.3102/0034654306298273

Schwier, R. A. (2001). Catalysts, emphases and elements of virtual learning communities: Implications for research and practice. The Quarterly Review of Distance Education, 2(1), 5-18.

Shulman, L. S. (1986). Those who understand: Knowledge growth in teaching. Educational Researcher, 15(2), 4-14. http://dx.doi.org/10.3102/0013189X015002004

Shulman, L. S. (1987). Knowledge and teaching: Foundations of the new reform. Harvard Educational Review, 57(1), 1-23. http://dx.doi.org/10.17763/haer.57.1.j463w79r56455411

Tharp, R. G., \& Gallimore, R. (1991). Rousing minds to life: Teaching, learning, and schooling in social context. New York, NY: Cambridge University Press.

Tolman, C. (1999). Society versus context in individual development: Does theory make a difference? In Y. Engeström, R. Miettinen \& R. Punamäki (Eds.), Perspectives on activity theory (pp. 70-87). New York, NY: Cambridge University Press.

Trust, T. (2015). Deconstructing an online community of practice: teachers' actions in the Edmodo math subject community. Journal of Digital Learning in Teacher Education, 31(2), 73-81. http://dx.doi.org/10.1080/21532974.2015.1011293

Villegas-Reimers, E. (2003). Teacher professional development: An international review of the literature. Paris, France: International Institute for Educational Planning.

Visser, R. D., Evering, L. C., \& Barrett, D. E. (2014). \#TwitterforTeachers: The implications of Twitter as a self-directed professional development tool for K-12 teachers. Journal of Research on Technology in Education, 46(4), 396-413. http://dx.doi.org/10.1080/15391523.2014.925694

Vygotsky, L. S. (1978). Mind in society: The development of higher psychological processes. Cambridge, MA: Harvard University Press.

Webster-Wright, A. (2009). Reframing professional development through understanding authentic professional learning. Review of Educational Research, 79(2), 702-739. http://dx.doi.org/10.3102/0034654308330970

Wenger, E. (1999). Communities of practice: Learning, meaning, and identity. New York, NY: Cambridge University Press. 
U.S. Department of Education, Office of Educational Technology. (2011). Connect and inspire: Online communities of practice in education. Retrieved from https://lincs.ed.gov/professionaldevelopment/resource-collections/profile-706.

Corresponding author: Torrey Trust, torrey@umass.edu

Australasian Journal of Educational Technology (c) 2017.

Please cite as: Trust, T. (2017). Using cultural historical activity theory to examine how teachers seek and share knowledge in a peer-to-peer professional development network. Australasian Journal of Educational Technology, 33(1), 98-113. https://doi.org/10.14742/ajet.2593 